TITLE:

\title{
Biodiesel production from rapeseed oil by various supercritical carboxylate esters
}

AUTHOR(S):

Goembira, Fadjar; Matsuura, Kosuke; Saka, Shiro

CITATION:

Goembira, Fadjar ...[et al]. Biodiesel production from rapeseed oil by various supercritical carboxylate esters. Fuel 2012, 97: 373-378

ISSUE DATE:

2012-07

URL:

http://hdl.handle.net/2433/156289

RIGHT:

(C) 2012 Elsevier Ltd.; This is not the published version. Please cite only the published version.; この論文は出版社版でありません。引用の際に は出版社版をご確認ご利用ください。 


\title{
Biodiesel Production from Rapeseed Oil by Various Supercritical Carboxylate Esters
}

\author{
Fadjar Goembira, Kosuke Matsuura, Shiro Saka* \\ Graduate School of Energy Science, Kyoto University \\ Yoshida-honmachi, Sakyo-ku, Kyoto 606-8501, Japan \\ *To whom correspondence should be addressed \\ Tel/Fax: +81-75-753-4738 \\ E-mail: saka@energy.kyoto-u.ac.jp
}

\begin{abstract}
Biodiesel is commonly produced from triglyceride and methanol, with glycerol as the by-product. This process has caused the overproduction of glycerol, which leads to its price devaluation and its likelihood to become a new type of waste. In this research, therefore, we explored the potential of converting rapeseed oil into fatty acid alkyl esters (FAAE) and triacins, instead of glycerol, by using supercritical carboxylate ester treatments in a batch-reaction system. As a result, it was found out that at reaction temperature of $350^{\circ} \mathrm{C}$ and pressures up to $17.8 \mathrm{MPa}$, interesterifications of triglyceride with various carboxylate esters have occurred without using any catalysts under supercritical condition, producing FAAE and triacins. Among all supercritical carboxylate esters, supercritical methyl acetate showed the highest product yield, i.e., 97.7wt\%, when both FAAE and triacin were considered as the product. Additionally, the mixture of FAAE and triacin in 3:1 molar ratio exhibited no detrimental effects on biodiesel quality.
\end{abstract}

Keywords: biodiesel; rapeseed oil; supercritical carboxylate esters; fatty acid alkyl esters; triacins 


\section{Introduction}

Presently, the world is still very much relying on fossil-fuel resources to fulfill its energy demands [1]. However, recently there have been global initiatives to discover renewable energy sources due to at least two main reasons. First, due to anxieties on the fluctuation of fossil-fuel prices in the world, with an increasing trend line. Second, due to concerns on some environmental issues, such as air-pollutions and global warming, originated from the use of fossil fuels [2].

Biodiesel is an alternative of petro-diesel, which has several benefits, such as its applicability to be used individually or blended with petro-diesel in diesel engines, without requiring any engine modifications. Moreover, it emits lower emissions on most air pollutants compared to those emitted from the combustion of petro-diesel, such as sulfur dioxides, carbon monoxide and particulate matters [3]. And lastly, it is produced from renewable resources, such as vegetable oils, waste cooking oils, animal fats etc.

For biodiesel production, the most popular method is transesterification of triglyceride with short-chain alcohols using an alkaline-catalyzed method. Although using moderate reaction conditions, however, this method is also known to have several issues related to the use of the catalysts, i.e., its sensitivity to water and free fatty acid contents in the feedstock. The presence of water in biodiesel feedstock can reduce catalyst performance, and eventually reducing product yields. Meanwhile, free fatty acid contained in the feedstock can react with the alkaline catalyst to produce saponified products, which complicates product purification [4]. Both issues have reduced the possible use of inexpensive feedstock such as animal fats and waste cooking oils. In addition, the process also will not be applicable for some potential inedible feedstock that has high free fatty acid contents such as Pongamia pinnata [5] and Jatropha curcas [6]. Due to the need for using refined feedstock, most of biodiesel 
producing countries currently use edible feedstock, such as soybean in the United States, rapeseed oil in Europe and palm oil in South East Asia [1]. However, the use of this conventional feedstock has led to a high biodiesel production cost, which could reduce its price competitiveness towards petro-diesel. Furthermore, this could also lead to a competition between crops for food and crops for energy, which could make the world encounter both energy and food crisis.

A non-catalyzed method called Saka process (one-step supercritical methanol method) was, therefore, developed to overcome any issues related to the use of catalysts [7]. This process was further improved by Saka-Dadan process (two-step supercritical methanol method) that uses milder reaction conditions [8]. The main advantages of the new processes are short reaction time, simple product purification and broad-range feedstock applicability.

Nevertheless, a new issue has emerged related to crude glycerol by-production, which is inevitable in biodiesel production from vegetable oils. The increase of crude glycerol by-production is a direct consequence towards worldwide biodiesel production growth, which has lead to the reduction of the by-product price [9]. If the oversupplied by-product could not be utilized, it would then become a new type of waste that will burden both biodiesel producers and the environment. In order to prevent glycerol byproduction, Saka and Isayama process was developed by utilizing methyl acetate instead of methanol in biodiesel production under supercritical condition [10]. The new non-catalytic method has been proven to convert triglyceride into fatty acid methyl esters (FAME) and triacetin, instead of glycerol. Furthermore, triacetin as a miscible by-product shows hardly any detrimental effects towards fuel quality [11].

Due to the availability of various types of carboxylate esters, it is interesting to know the applicability of different types of those esters on biodiesel production under 
supercritical condition. Reaction formulae (1) and (2) compare triglyceride conversion into biodiesel through interesterification by supercritical carboxylate ester and transesterification by methanol in an alkali-catalyzed process, respectively. We can clearly see the absence of glycerol formation in the first-mentioned reaction mechanism.

$$
\begin{aligned}
& \mathrm{CH}_{2}-\mathrm{OCOR}_{1} \quad \mathrm{R}_{1} \mathrm{COOR}_{\mathrm{B}} \quad \mathrm{CH}_{2}-\mathrm{OCOR}_{\mathrm{A}}
\end{aligned}
$$

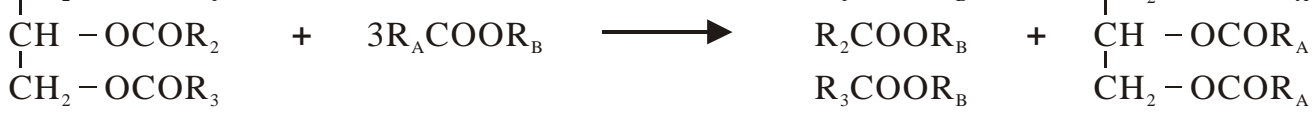

$$
\begin{aligned}
& \begin{array}{cccc}
\text { Triglyceride } & \begin{array}{c}
\text { Carboxylate } \\
\text { ester }
\end{array} & \text { FAAE } & \text { Triacin }
\end{array}
\end{aligned}
$$

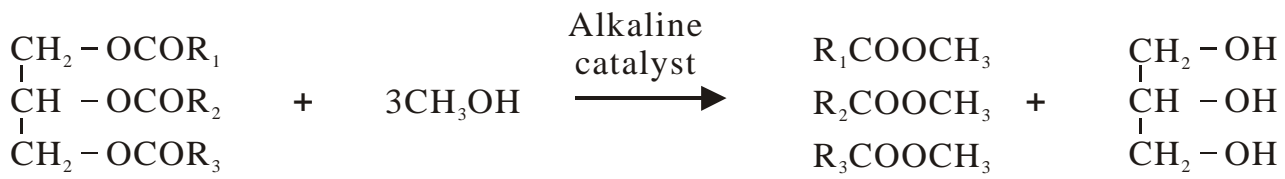

$$
\begin{aligned}
& \begin{array}{llll}
\text { Triglyceride } & \text { Methanol Glycerol }
\end{array} \\
& \mathrm{R}_{1}, \mathrm{R}_{2}, \mathrm{R}_{3} \text {; hydrocarbon residues } \\
& \mathrm{R}_{\mathrm{A}} \text { : alkyl residue in acyl moiety, } \mathrm{R}_{\mathrm{B}} \text { : alkyl residue in alcohol moiety }
\end{aligned}
$$

This paper is, therefore, made to show the reactivity of triglyceride with a variety of carboxylate esters in biodiesel production under supercritical condition without using any catalysts. In addition, evaluation of some fuel properties on the mixture of fatty acid alkyl esters (FAAE) and triacins is also addressed in this paper.

\section{Materials and methods}

\subsection{Materials}

Rapeseed oil purchased from Nacalai Tesque Inc, Kyoto was used as the source of triglyceride, which contains free fatty acid less than $1 \mathrm{wt} \%$. Meanwhile, twelve types of carboxylate esters (purity $>99 \%$ ) as shown in Table 1 were used as solvents and obtained from the same manufacturer. The critical points of each carboxylate ester [1214] are shown in the same table.

Molar ratio of carboxylate ester to oil of 42:1 was used in order to proceed the reaction towards the product side. In addition, volumetric ratio of carboxylate ester to oil is presented in Table 1, which clearly shows that in achieving the determined 
carboxylate ester to oil molar ratio; methyl acetate and butyl butyrate used the least and the most carboxylate ester volumes for one experimental run, respectively. Moreover, theoretical maximum biodiesel yields, i.e., the total amount of FAAE and triacin, for each carboxylate ester are also shown in Table 1.

Furthermore, Table 2 shows expected products from interesterification of triglyceride by various supercritical carboxylate esters, where FAME, FAEE, FAPE and FABE stand for fatty acid methyl esters, fatty acid ethyl esters, fatty acid propyl esters and fatty acid butyl esters, respectively. Analytical grade of various alkyl esters and triacins such as triacetin, tripropionin and tributyrin were used as standard compounds for those expected products, which were brought from Nacalai Tesque Inc, Kyoto.

\subsection{Supercritical carboxylate ester treatment}

A batch-reaction vessel was used for the supercritical carboxylate treatments of rapeseed oil. The 5ml-volume capacity reaction vessel is made of Inconnel-625 that can stand temperatures up to $500^{\circ} \mathrm{C}$ and $200 \mathrm{MPa}$ of pressure. A thermocouple and a pressure gauge were attached to the reaction vessel for real time measurement of reaction temperatures and pressures. Reaction temperature was set at $350^{\circ} \mathrm{C}$, while reaction pressures could be accurately controlled in the batch-reaction system, but differed for different carboxylate esters as shown in Table 1. To achieve supercritical condition, the reaction vessel was immersed in a tin bath for a certain period of time, and then it was cooled down by using a water bath to stop the reaction instantly. Reaction time was set at 15,30 and $45 \mathrm{~min}$.

\subsection{Analysis of products}

Biodiesel products consisted of FAAE and triacin, were separated from unused carboxylate ester by using a rotary evaporator connected to a vacuum pump. The 
obtained biodiesel was analyzed by using high performance liquid chromatography (HPLC), with the following set up; column: Cadenza CD-C18, oven temperature: $40^{\circ} \mathrm{C}$, mobile phase: methanol, flow rate: $1 \mathrm{~mL} / \mathrm{min}$, detector: refractive index detector (RID).

Calculation of FAAE and triacin yields was initiated by identification of FAAE and triacin peaks in HPLC chromatograms through comparison of them with retention time of corresponding FAAE and triacin standard compounds. Subsequently, the quantification of FAAE and triacin contents in sample was conducted by comparing a peak area of products with standard calibration curves obtained from standard compounds.

\subsection{Fuel property analysis}

Model fuels made of selected FAAE and triacins were used in this experiment to check some important fuel properties. Density was checked by using the I-type floating density test method specified in JIS K2249, while kinematic viscosity was measured by using automatic kinematic viscosity test apparatus AKV-201. Pour point and cold filter plugging point were quantified by using automatic pour point test apparatus MPC-102L and automatic cold filter plugging point test apparatus AFP-102, respectively. In addition, flash point was determined by using Pensky-Martens closed cup flash point measurement apparatus APM-7, while 100\% residual carbon fraction was checked by using micro residue carbon fraction measurement apparatus ACR-M3 (manufactured by Tanaka Kagaku Kiki).

\section{Results and Discussions}

\subsection{Interesterification of triglyceride by supercritical carboxylate esters}

Fig. 1 shows HPLC chromatograms of rapeseed oil as supercritically treated by carboxylate esters for $45 \mathrm{~min}$. From this figure, we can see that all supercritical carboxylate ester treatments could convert triglyceride into FAAE and triacins. 
Despites the strong peaks of alkyl oleate $\left(\mathrm{C}_{\mathrm{A} 18: 1}\right)$ and corresponding triacins that appear in all chromatograms, the presence of alkyl linolenate $\left(\mathrm{C}_{\mathrm{A} 18: 3}\right)$, linoleate $\left(\mathrm{C}_{\mathrm{A18:2}}\right)$ and stearate $\left(\mathrm{C}_{\mathrm{A} 18: 0}\right)$ peaks were only clearly observed in supercritical methyl acetate treatment. This shows that supercritical methyl acetate treatment has the highest reactivity towards all fatty acids presented in the feedstock. In addition, the appearance of strong alkyl oleate in all chromatograms is due to the use of rapeseed oil that contains approximately $61.5 \mathrm{wt} \%$ oleic acid.

Furthermore, from Fig. 1 we could also see that peak retention time of FAAE in is influenced by the length of alkyl chain, i.e., the longer peak retention time due to the longer alkyl chain in the alcohol moiety. Whereas for triacins, the length of alkyl chain in the acyl moiety contributed to the retention time of triacin peaks. Additionally, the disappearance of product intermediates was also observed, particularly in supercritical methyl acetate treatment. This could give an initial indication that the highest reactivity was achieved by supercritical methyl acetate treatment.

Regarding to quantification of the products, Figs. 1 and 2 present the yields of FAAE and triacin, respectively, as rapeseed oil was treated in various supercritical carboxylate esters for 15,30 and $45 \mathrm{~min}$. In case of FAAE, only supercritical methyl acetate and supercritical ethyl acetate treatments achieved yields more than $50 \mathrm{wt} \%$. Among all supercritical carboxylate ester treatments, the highest FAAE yields were attained by supercritical methyl acetate, i.e., 60.4, 80.2 and $89.7 \mathrm{wt} \%$ after 15,30 and 45min, correspondingly. In addition, from Fig. 2, we can also clearly see that all yields were increased when the reaction time was raised from 15 to $30 \mathrm{~min}$. However, the yield increase was not observed in all treatments when the reaction time was set to 45min, which could be due to possible thermal decomposition of FAAE products during the supercritical treatment. Particularly for FAME, thermal decomposition at 
high reaction temperature under high reaction pressure has been reported by Imahara et al. [15] for supercritical methanol treatment. The same thermal decomposition phenomenon is presumed to occur in all supercritical carboxylate ester treatments, especially when the reaction pressures were relatively low, thus measurement of the reaction pressure is a prerequisite for understanding the supercritical treatment [16].

As for triacin yields presented in Fig. 3, supercritical methyl acetate treatment also achieved the highest yield, compared to the other carboxylate esters, although the yield was not as high as that of FAAE. Relatively low triacin yield could be due to at least two reasons. First, the formation of one triacin molecule required a complete removal of acyl parts attached to the glycerol backbone in triglyceride and their replacements with ones from carboxylate esters. Therefore, the presence of product intermediates could indicate the likelihood of low triacin yield. The second reason could be due to possible thermal decomposition of triacins at high reaction temperature, $350^{\circ} \mathrm{C}$.

Furthermore, based on Table 2, when we consider the same alkyl residue in the acyl moiety but different alkyl residue in the alcohol moiety, we could make a comparison on the yield of different FAAE. For instance, in the first row of the table, the products consisted of FAME, FAEE, FAPE or FABE and triacetin. Regarding to this grouping and in accordance to Fig. 2, as the length of alkyl chain increased in the alcohol moiety, the yield of FAAE decreased. This situation can also be observed, when ethyl and propyl residues were the alkyl chains of the acyl moiety. In conclusion, for the same alkyl residue in the acyl moiety, FAAE yields from the higher to the lower are in the following order; FAME $>$ FAEE $>$ FAPE $>$ FABE.

As for the triacin yields, the comparison could be based on the same alkyl residue in the alcohol moiety and different alkyl residues in the acyl moiety. For example, based on Table 2, when the alkyl residue is methyl group, we could compare the yield 
of triacetin, tripropionin and tributyrin that were formed together with FAME as the FAAE. A similar trend showed by this grouping, i.e., the shorter alkyl residue in acyl moiety resulted in the higher yield of triacin. As a conclusion, triacin yields from the same alkyl residue in the alcohol moiety are in the following order; triacetin>tripropionin>tributyrin.

Based on the discussions on results presented in Figs. 2 and 3, supercritical methyl acetate treatment showed the highest for both FAAE and triacin yields, compared to the rest supercritical carboxylate ester treatments, i.e., $89.7 \mathrm{wt} \%$ for FAME and $8.0 \mathrm{wt} \%$ for triacetin, after $45 \mathrm{~min}$ reaction time. Higher reactivity of supercritical methyl acetate compared to the other supercritical carboxylate esters could be due to the highest reaction pressure achieved, which increased the chance of on-going reaction. As shown in Table 1, reaction pressures were varied depending on the type of carboxylate esters used. As the alkyl chain in both alcohol and acyl moieties became longer, the obtained reaction pressure in the batch-type reaction vessel became lower. Warabi et al. [17] reported the effect of reaction pressure on the yield of FAME in supercritical methanol treatment, which showed that lower reaction pressures resulted in the lower yields. Higher reaction pressure under the same reaction temperature in supercritical treatment contributed to the increase of the solvent density in the system. Turro [18] explains that at sufficiently high densities, collisions between solute molecules occur in sets, and collisions will further increase as the density of solvent particles is increased. This explanation could be in agreement with the fact that the higher reaction pressures resulted in higher density of reagents in supercritical treatment.

Additionally, Fig. 4 shows FAME yield of rapeseed oil as treated in supercritical methyl acetate at reaction time shorter than $15 \mathrm{~min}$, and its comparison with FAME yields from supercritical dimethyl carbonate and supercritical methanol as reported by 
Ilham and Saka [19]. We can see from the figure that lower reactivity shown by supercritical methyl acetate treatment. In supercritical methanol treatment, under $350^{\circ} \mathrm{C} / 43 \mathrm{MPa}, 6 \mathrm{~min}$ reaction time was needed for an almost completed reaction. Meanwhile, when we use supercritical dimethyl carbonate, under the lower pressure of $20 \mathrm{MPa}$ at $350^{\circ} \mathrm{C}, 15 \mathrm{~min}$ reaction time was required for similar yield. Despite the fact that the lower reaction pressure of $17.8 \mathrm{MPa}$ at $350^{\circ} \mathrm{C}$ was achieved by supercritical methyl acetate treatment, which contributed to the lower yield, the other possible cause could be due to the property of solvents used in the treatments. Among the three carboxylate esters, only methyl acetate is considered as a weakly polar solvent that could be confirmed by its miscibility with rapeseed oil at room temperature and pressure. At one point, the miscibility is an advantage for methyl acetate to overcome the mass transfer issue faced by methanol and dimethyl carbonate. However, the weak solvent polarity could somehow contribute to lower reactivity of methyl acetate, even at its supercritical state. This situation further explains the need for the longer reaction time in supercritical methyl acetate treatment to achieve comparable yield with supercritical methanol and supercritical dimethyl carbonate. Moreover, due to the need for longer reaction time in supercritical methyl acetate, the maximum achievable yield was not as high as those obtained by supercritical methanol and supercritical dimethyl carbonate. This situation is most probably caused by higher degree of thermal decomposition that occurred at longer reaction time at supercritical methyl acetate treatment. It is, therefore, very important to find out any possible measures in increasing the reactivity of supercritical methyl acetate in order to shorten the reaction time, in future studies. 


\subsection{Effects of blending triacin with $F A A E$ on fuel properties}

Fuel properties were examined by using model fuels and the obtained results are shown in Table 3. Two FAAE, represented by methyl oleate and ethyl oleate, and two types of triacins, i.e., triacetin and tributyrin were used in this measurement. A choice of methyl oleate and ethyl oleate was due to the fact that both methyl and ethyl carboxylate esters produced the highest biodiesel yields as shown in Fig. 2, compared to propyl and butyl carboxylate esters in supercritical treatments. Furthermore, the selection of triacetin and tributyrin was to give a range of fuel property values among the lightest and the heaviest molecular weight of triacins that could be obtained by supercritical carboxylate ester treatments. The model biodiesel fuels were defined as 3:1 molar ratio of methyl oleate or ethyl oleate to triacins (triacetin or tributyrin).

Based on Table 3, it can be seen that blending triacins to FAAE could increase the density of the mixture. However, the increase is still acceptable, particularly for the US standard which has no requirement on biodiesel density. In addition, although high fuel density means that a vehicle will bring heavier fuel for a certain amount of volume, it means that more quantity of energy is available for that amount of fuel.

A more important fuel property is the kinematic viscosity, which is related to the possibility of the fuel to be atomized and sprayed into the combustion chamber of engine. High fuel viscosity could potentially damage engine due to poor fuel atomization, which enhances engine deposits and ruins fuel pump components and injectors [20]. Based on Table 3, all kinematic viscosity values of the model biodiesel can satisfy the standard requirements.

As for the cold flow properties, it can be concluded from Table 3 that triacins, particularly triacetin, are very good in reducing pour point and cold filter plugging 
point. The cold flow properties are very important factors to consider, particularly for biodiesel application in regions with extremely cold seasonal weather.

Lastly, carbon residue is fuel property that relates to the potential of carbon formation in the combustion chamber during fuel usage. The mixture of FAAE and triacins seems to increase the values of carbon residue as shown in Table 3. However, the increase is still within the limit as required by the referred fuel standards.

\section{Concluding remarks}

The use of various supercritical carboxylate esters could convert triglyceride into FAAE and triacins in the absence of any catalysts. The highest product yield was shown by supercritical methyl acetate treatment, which was $97.7 \mathrm{wt} \%$ when we consider the mixture of both FAME and triacetin as biodiesel. Lower reactivity shown by other carboxylate esters could be due to the length of alkyl chains in the esters, i.e., the longer alkyl chains in both alcohol and acyl moieties of carboxylate esters gave the lower product yields. Furthermore, different reactivity of supercritical carboxylate ester treatments for triglyceride could also be due to different maximum reaction pressures that were achieved in the batch-reaction system for each ester, i.e., the lower reaction pressures resulted in the lower product yields. Supercritical carboxylate ester treatments have been proven not to produce glycerol, therefore, any issues regarding to glycerol by-production in biodiesel production from triglyceride can be solved. Furthermore, it has been proven that the mixtures of FAAE and triacins have no detrimental effects on fuel properties. In fact, some important fuel properties such as pour point and cold filter plugging point were improved due to the mixture of the two compounds. The prevention of glycerol by-production combined with the advantages of FAAE and triacin mixtures have put supercritical carboxylate esters, particularly 
supercritical methyl acetate, as a prospective alternative in biodiesel production from triglyceride.

\section{References}

[1] Lin L, Cunshan Z, Vittayapadung S, Xiangqian S, Mingdong D. Opportunities and challenges for biodiesel fuel. Appl Energy 2001;88:1020-31.

[2] $\mathrm{Ng} \mathrm{JH}, \mathrm{Ng} \mathrm{HK}$, Gan S. Recent trends in policies, socioeconomy and future directions of the biodiesel industry. Clean Techn Environ Policy 2009; DOI 10.1007/s10098-009-0235-2.

[3] Fazal MA, Haseeb ASMA, Masjuki HH. Biodiesel feasibility study: An evaluation of material compatibility; performance; emission and engine durability. Renew Sustain Energy Rev 2011;15:1314-24.

[4] Ma F, Clements LD, Hanna MA. The effects of catalyst, free fatty acids and water on transesterification of beef tallow. Trans ASAE 1998;41:1261-4.

[5] Goembira F, Saka S. Pongamia pinnata as potential biodiesel feedstock. In: Yao T, editor. Green Energy and Technology, Zero-Carbon Energy Kyoto 2010, Tokyo: Springer; 2011,Part II (iii):111-6.

[6] Makkar HPS, Becker K. Jatropha curcas, a promising crop for the generation of biodiesel and value-added coproducts. Eur J Lipid Sci Technol 2009;111:773-87.

[7] Saka S, Kusdiana D. Biodiesel fuel from rapeseed oil as prepared in supercritical methanol. Fuel 2001;80:225-31.

[8] Kusdiana D, Saka S. Two-step preparation for catalyst-free biodiesel fuel production. Appl Biochem Biotechnol 2004;113-116:781-91.

[9] Bonet J, Costa J, Romain S, Reneaume JS, Pleşu AE, Pleşu V et al. Revalorization of glycerol: Comestible oil from biodiesel synthesis. Food Bioprod Proc 2009;87:171-8.

[10] Saka S. Manufacturing method for fatty acid methyl esters. Japan Patent No. 4378534 (application: 19 December 2005; granted 2 October 2009).

[11] Saka S, Isayama Y. A new process for catalyst-free production of biodiesel using supercritical methyl acetate. Fuel 2009;88:1307-13.

[12] Yaws CL (Ed.). Chemical Properties Handbook. McGraw-Hill. 1999

[13] Knovel Critical Tables (2nd Edition). Knovel. 2008

[14] Design Institute for Physical Properties. DIPPR Project 801 - Full version. 2010 
[15]Imahara H, Minami E, Hari S, Saka S. Thermal stability of biodiesel in supercritical methanol. Fuel 2008;87:1-6.

[16]Saka S, Goembira F, Ilham Z. Comment on "A glycerol-free process to produce biodiesel by supercritical methyl acetate technology: An optimization study via response surface methodology". Bioresour Technol 2011; doi: 10.1016/j.biortech.2010.11.001.

[17]Warabi Y, Kusdiana D, Saka S. Biodiesel fuel from vegetable oil by various supercritical alcohols. Appl Biochem Biotech 2004;113-116:793-801.

[18]Turro NJ. Molecular structure as a blueprint for supramolecular structure chemistry in confined spaces. PNAS 2005;102:10766-70.

[19]Ilham Z, Saka S. Dimethyl carbonate as potential reactant in non-catalytic biodiesel production by supercritical method. Bioresour Technol 2009;100:1793-6.

[20]Alptekin E, Canakci, M. Determination of the density and viscosity of biodieseldiesel fuel blends. Renew Energy 2008;33:2623-30. 


\section{Figure captions}

Fig. 1 HPLC chromatograms of rapeseed oil as treated in supercritical carboxylate esters at $350^{\circ} \mathrm{C} / \sim 17.8 \mathrm{MPa} / 45 \mathrm{~min}$

Fig. 2 FAAE yields of rapeseed oil as treated in supercritical carboxylate esters at $350^{\circ} \mathrm{C} / \sim 17.8 \mathrm{MPa} / \sim 45 \mathrm{~min}$ (black bars: FAAE; black + grey bars: theoretical maximum)

Fig. 3 Triacin yields of rapeseed oil as treated in supercritical carboxylate esters at $350^{\circ} \mathrm{C} / 17.8 \mathrm{MPa} / \sim 45 \mathrm{~min}$ (black bars: triacin; black + grey bars: theoretical maximum)

Fig. 4 FAME yields of rapeseed oil as treated in supercritical methanol, supercritical dimethyl carbonate and supercritical methyl acetate at 42:1 molar ratio of carboxylate ester to oil 
Table 1 Various carboxylate esters used for biodiesel production in supercritical treatments

\begin{tabular}{|c|c|c|c|c|c|c|}
\hline \multirow{2}{*}{$\begin{array}{c}\text { Carboxylate } \\
\text { esters }\end{array}$} & \multicolumn{2}{|c|}{ Critical point } & \multirow{2}{*}{$\begin{array}{c}\text { Reaction } \\
\text { pressure at } \\
350^{\circ} \mathrm{C}, \mathrm{MPa}\end{array}$} & \multirow{2}{*}{$\begin{array}{l}\text { Molar ratio of } \\
\text { solvent to oil } \\
\text { (vol. ratio) }\end{array}$} & \multicolumn{2}{|c|}{ Theoretical maximum, wt $\%$} \\
\hline & $\begin{array}{l}\mathrm{Tc}, \\
{ }^{\circ} \mathrm{C}\end{array}$ & $\begin{array}{l}\mathrm{Pc}, \\
\mathrm{MPa}\end{array}$ & & & FAAE & Triacin \\
\hline \multicolumn{7}{|l|}{ Methyl carboxylates } \\
\hline Methyl acetate & 234 & 4.6 & 17.8 & $42(3.4)$ & 100 & 25 \\
\hline Methyl propionate & 258 & 4.0 & 15.4 & $42(4.1)$ & 100 & 29 \\
\hline Methyl butyrate & 281 & 3.5 & 11.2 & $42(4.9)$ & 100 & 34 \\
\hline \multicolumn{7}{|l|}{ Ethyl carboxylates } \\
\hline Ethyl acetate & 250 & 3.9 & 16.3 & $42(4.2)$ & 100 & 23 \\
\hline Ethyl propionate & 273 & 3.4 & 14.5 & $42(4.9)$ & 100 & 28 \\
\hline Ethyl butyrate & 293 & 3.1 & 10.9 & $42(5.7)$ & 100 & 32 \\
\hline \multicolumn{7}{|l|}{ Propyl carboxylates } \\
\hline Propyl acetate & 276 & 3.2 & 14.2 & $42(4.9)$ & 100 & 22 \\
\hline Propyl propionate & 305 & 3.0 & 10.4 & $42(5.7)$ & 100 & 27 \\
\hline Propyl butyrate & 327 & 2.7 & 4.6 & $42(6.4)$ & 100 & 31 \\
\hline \multicolumn{7}{|l|}{ Butyl carboxylates } \\
\hline Butyl acetate & 306 & 3.1 & 9.2 & $42(5.7)$ & 100 & 22 \\
\hline Butyl propionate & 322 & 2.8 & 7.4 & $42(6.4)$ & 100 & 26 \\
\hline Butyl butyrate & 339 & 2.6 & 3.1 & $42(7.1)$ & 100 & 30 \\
\hline
\end{tabular}


Table 2 Expected products of FAAE and triacins from interesterification of triglyceride in supercritical carboxylate esters $\left(\mathrm{R}_{\mathrm{A}} \mathrm{COOR}_{\mathrm{B}}\right)$

\begin{tabular}{|c|c|c|c|c|c|c|}
\hline \multirow{2}{*}{$\mathrm{R}_{\mathrm{A}} \mathrm{COOR}_{\mathrm{B}}$} & & \multicolumn{4}{|c|}{$\mathrm{R}_{\mathrm{B}}$ (alkyl residue in alcohol moiety) } & \multirow{2}{*}{ Triacin } \\
\hline & & $-\mathrm{CH}_{3}$ & $-\mathrm{C}_{2} \mathrm{H}_{5}$ & $-\mathrm{C}_{3} \mathrm{H}_{7}$ & $-\mathrm{C}_{4} \mathrm{H}_{9}$ & \\
\hline \multirow{4}{*}{$\begin{array}{c}\mathrm{R}_{\mathrm{A}} \\
\text { (alkyl residue in } \\
\text { acyl moiety) }\end{array}$} & $\mathrm{CH}_{3^{-}}$ & $\begin{array}{l}\text { Methyl } \\
\text { acetate }\end{array}$ & $\begin{array}{l}\text { Ethyl } \\
\text { acetate }\end{array}$ & $\begin{array}{l}\text { Propyl } \\
\text { acetate }\end{array}$ & $\begin{array}{l}\text { Butyl } \\
\text { acetate }\end{array}$ & Triacetin \\
\hline & $\mathrm{C}_{2} \mathrm{H}_{5^{-}}$ & $\begin{array}{c}\text { Methyl } \\
\text { propionate }\end{array}$ & $\begin{array}{c}\text { Ethyl } \\
\text { propionate }\end{array}$ & $\begin{array}{c}\text { Propyl } \\
\text { propionate }\end{array}$ & $\begin{array}{c}\text { Butyl } \\
\text { propionate }\end{array}$ & Tripropionin \\
\hline & $\mathrm{C}_{3} \mathrm{H}_{7^{-}}$ & $\begin{array}{l}\text { Methyl } \\
\text { butyrate }\end{array}$ & $\begin{array}{c}\text { Ethyl } \\
\text { butyrate }\end{array}$ & $\begin{array}{c}\text { Propyl } \\
\text { butyrate }\end{array}$ & $\begin{array}{c}\text { Butyl } \\
\text { butyrate }\end{array}$ & Tributyrin \\
\hline & & FAME & FAEE & FAPE & FABE & \\
\hline
\end{tabular}


Table 3 Fuel properties of methyl oleate, ethyl oleate, triacetin, tributyrin and model biodiesel compared to some biodiesel standards

\begin{tabular}{|c|c|c|c|c|c|c|c|c|c|c|c|c|}
\hline \multirow{2}{*}{$\begin{array}{c}\text { Fuel } \\
\text { property }\end{array}$} & \multirow[b]{2}{*}{ Unit } & \multirow{2}{*}{ FAME $^{[11]}$} & \multirow[b]{2}{*}{ FAEE } & \multirow{2}{*}{$\begin{array}{c}\text { Tri- } \\
\text { acetin }\end{array}$} & \multirow{2}{*}{$\begin{array}{c}\text { Tri- } \\
\text { butyrin }\end{array}$} & \multicolumn{4}{|c|}{ Model biodiesel } & \multicolumn{3}{|c|}{ Biodiesel standard } \\
\hline & & & & & & $\begin{array}{c}\text { FAME+ } \\
\text { Triacetin }^{[11]}\end{array}$ & $\begin{array}{l}\text { FAME+ } \\
\text { tributyrin }\end{array}$ & $\begin{array}{l}\text { FAEE+ } \\
\text { triacetin }\end{array}$ & $\begin{array}{c}\text { FAEE+ } \\
\text { tributyrin }\end{array}$ & Kyoto & EU & US \\
\hline Density $\left(15^{\circ} \mathrm{C}\right)$ & $\mathrm{g} / \mathrm{ml}$ & 0.88 & 0.87 & 1.16 & 1.04 & 0.92 & 0.91 & 0.91 & 0.91 & $0.86-0.90$ & $0.86-0.90$ & - \\
\hline $\begin{array}{l}\text { Kinematic } \\
\text { viscosity }\left(40^{\circ} \mathrm{C}\right)\end{array}$ & $\mathrm{mm}^{2} / \mathrm{s}$ & 4.4 & 4.7 & 7.3 & 5.5 & 4.5 & 4.6 & 4.7 & 4.7 & $3.5-5.0$ & $3.5-5.0$ & $1.9-6.0$ \\
\hline Pour point & ${ }^{\circ} \mathrm{C}$ & -16.0 & -21.0 & -40.0 & -60.0 & -18.0 & -18.0 & -20.0 & -22.0 & $\leq-7.5$ & - & - \\
\hline $\begin{array}{l}\text { Cold filter } \\
\text { plugging point }\end{array}$ & ${ }^{\circ} \mathrm{C}$ & -16.0 & -21.0 & -13.5 & -20.0 & -17.0 & -18.0 & -20.0 & -20.0 & $\leq-5.0$ & - & - \\
\hline Flash point & ${ }^{\circ} \mathrm{C}$ & 170.5 & 167.5 & 158.5 & 181.0 & 154.5 & 164.5 & 151.5 & 163.0 & $\geq 100$ & $\geq 101$ & $\geq 130$ \\
\hline $\begin{array}{l}\text { Carbon residue } \\
(100 \%)\end{array}$ & $\mathrm{wt} \%$ & 0.02 & 0.01 & 0.01 & 0.01 & 0.03 & 0.03 & 0.01 & 0.01 & $\begin{array}{l}\leq 0.30 \\
(10 \%)\end{array}$ & $\begin{array}{l}\leq 0.30 \\
(10 \%)\end{array}$ & $\leq 0.05$ \\
\hline
\end{tabular}




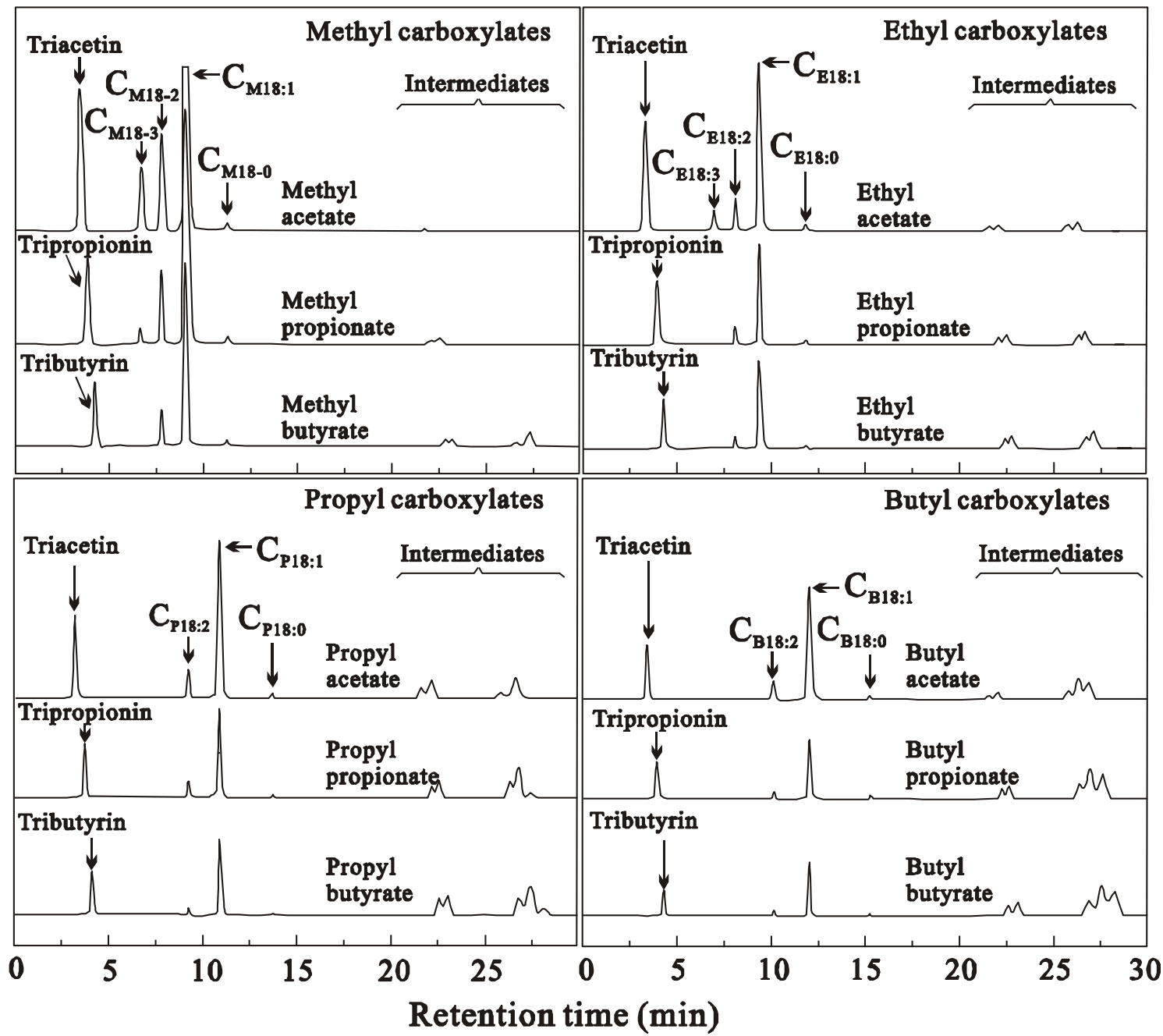

Fig. 1 HPLC chromatograms of rapeseed oil as treated in supercritical carboxylate esters at $350^{\circ} \mathrm{C} / \sim 17.8 \mathrm{MPa} / 45 \mathrm{~min}$ 


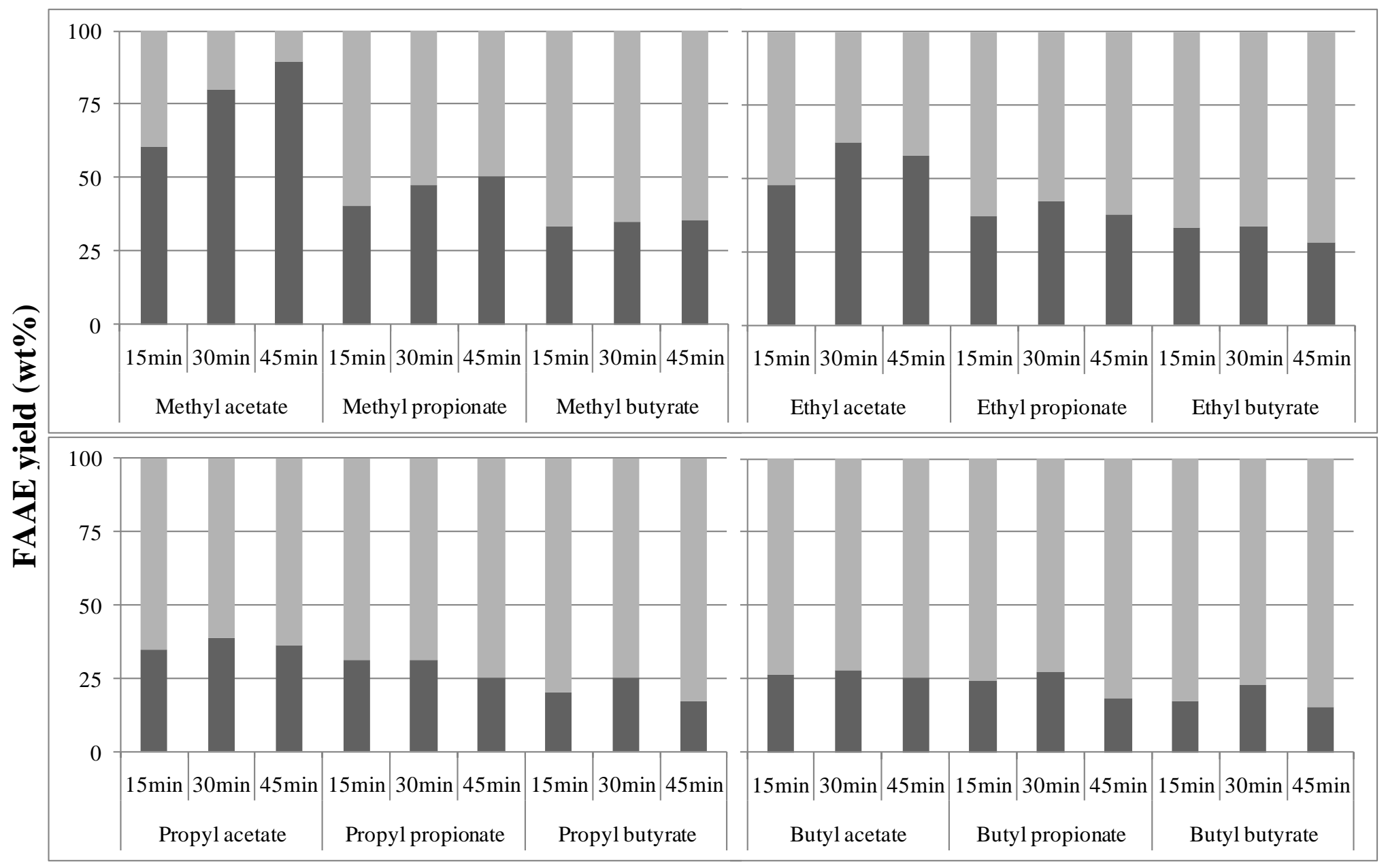

Fig. 2 FAAE yields of rapeseed oil as treated in supercritical carboxylate esters at $350^{\circ} \mathrm{C} / \sim 17.8 \mathrm{MPa} / \sim 45 \mathrm{~min}$ (black bars: FAAE; black + grey bars: theoretical maximum) 


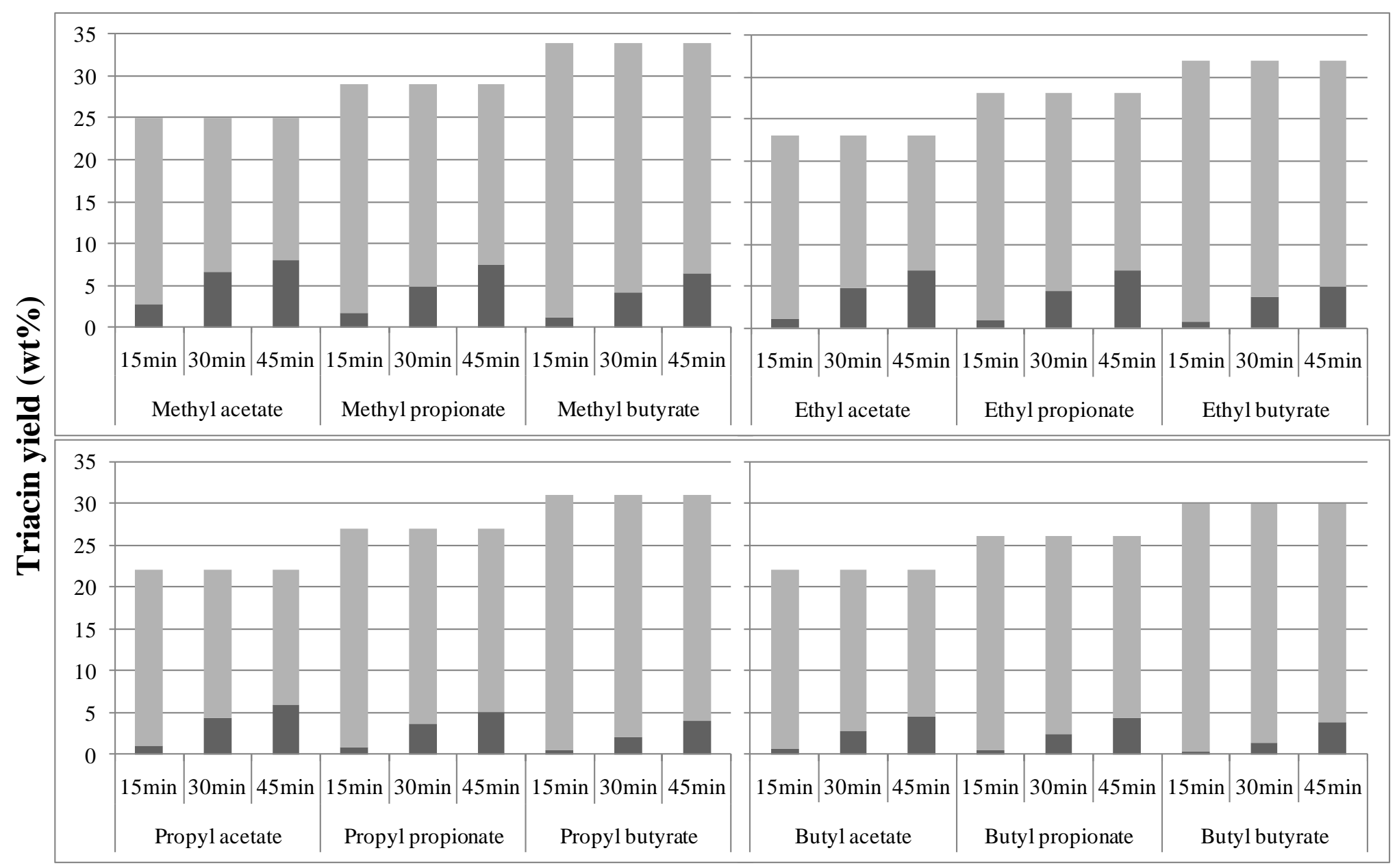

Fig. 3 Triacin yields of rapeseed oil as treated in supercritical carboxylate esters at $350^{\circ} \mathrm{C} / \sim 17.8 \mathrm{MPa} / \sim 45 \mathrm{~min}$ (black bars: triacin; black + grey bars: theoretical maximum) 


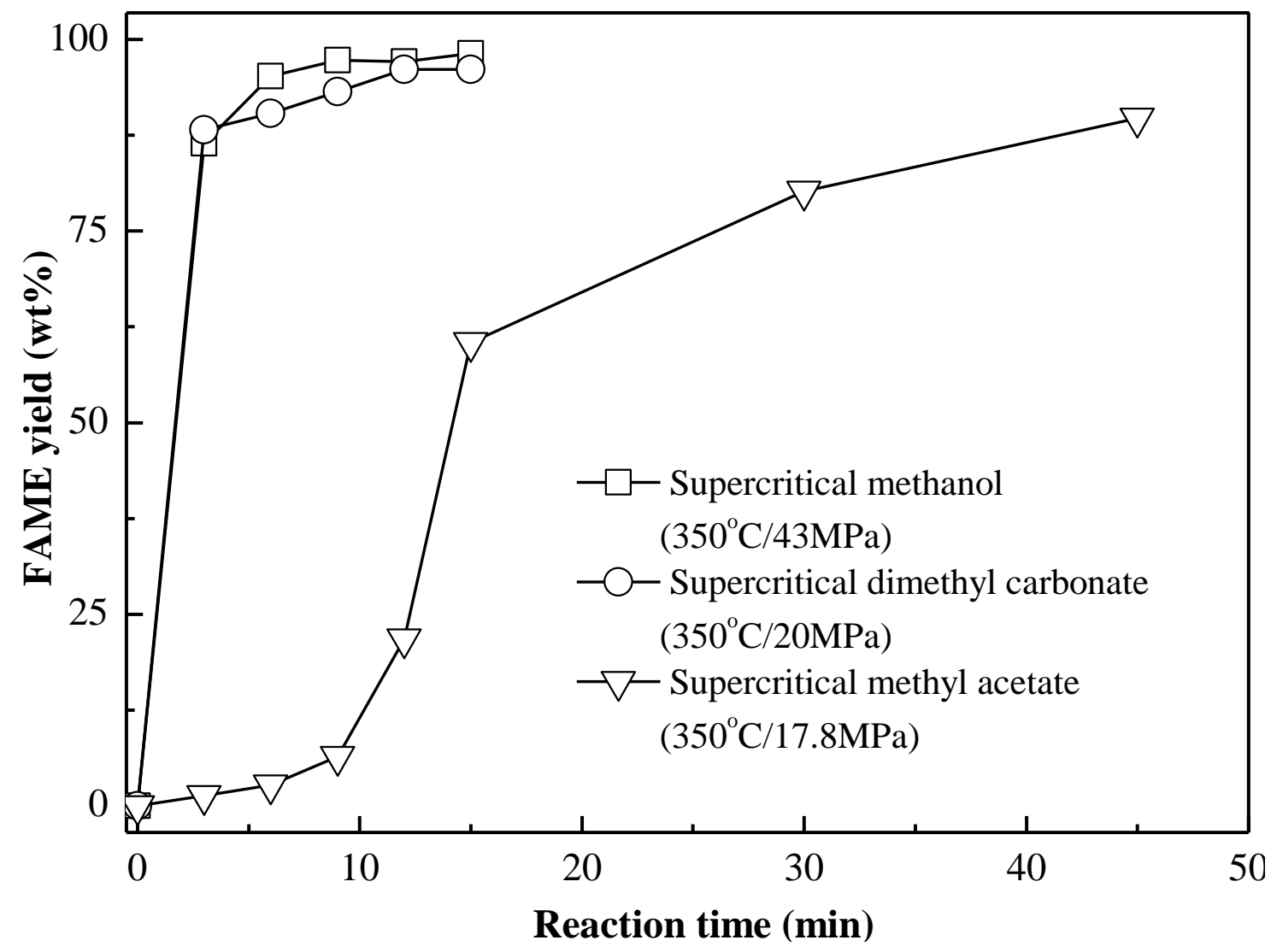

Fig. 4 FAME yields of rapeseed oil as treated in supercritical methanol, supercritical dimethyl carbonate and supercritical methyl acetate at 42:1 molar ratio of solvent to rapeseed oil 


\section{Highlights}

1. Various supercritical carboxylate esters without the presence of any catalysts could convert triglyceride (represented by rapeseed oil) into fatty acid alkyl esters (FAAE) and triacins as the by-product, instead of glycerol.

2. When both FAAE and triacin mixture was considered as the biodiesel product, supercritical methyl acetate attained the highest yield, i.e., $97.7 \mathrm{wt} \%$.

3. The longer the alkyl residues in alcohol or acyl moieties in carboxylate esters, the lower the yield would be.

4. Mixtures of FAAE and triacins gave hardly any detrimental effects on fuel properties. 